Journal of Energy and
Environmental Sustainability
Journal homepage : www.jees.in

\title{
Biomass and Hydrocarbon Production by Botryococcus braunii Using Supplemented Secondary Treated Wastewater
}

\author{
Maria Alejandra Cruz Salazar ${ }^{\mathrm{a}}$, Adenise Lorence Woiciechowski ${ }^{\mathrm{a}}$, Jesus David Coral Medina ${ }^{\mathrm{a}}$, \\ Arion Zandoná Filho ${ }^{\mathrm{b}}$, Carlos José Dalmas Neto ${ }^{\mathrm{a}}$, Satinder Kaur Brarc, Carlos Ricardo Soccol ${ }^{{ }^{*}}$. \\ a: Federal University of Parana. Department of Biotechnology and Bioprocess Engineering. CEP. 81531-970, Curitiba-PR, Brazil. \\ b: Federal University of Parana. Department of Chemical Engineering, Curitiba-PR, Brazil. \\ c: Institut National de la Recherche Scientifique (INRS), Eau, Terre et Environnement, Québec-Canada
}

A R T I C L E I N F O

Received : 01 May 2017

Revised : 30 May 2017

Accepted : 31 May 2017

Keywords:

B. braunii; biomass production;

hydrocarbon production; secondary treated wastewater.

\begin{abstract}
A B S T R A C T
The treatment of wastewater has been traditionally done by physical, chemical and biological process. A sequence of experiments was carried out to determine the best concentration of secondary treated wastewater that could be used as growth medium for B. braunii. It was found that $50 \%(\mathrm{v} / \mathrm{v})$ of treated wastewater and $50 \%(\mathrm{v} / \mathrm{v})$ of modified $\mathrm{BG}_{11}$ medium was adequate for microalgae growth. Different concentrations of three salts : sodium nitrate, ferric citrate and dipotassium phosphate were tested using central composite design (DCCR), and dipotassium phosphate was found to be statistically significant at $0.12 \mathrm{~g} \cdot \mathrm{l}^{-1}$ of this salt. Optimization of $\mathrm{CO}_{2}$ concentration and light intensity showed that $70 \mu \mathrm{mol} \cdot \mathrm{m}^{-2} \mathrm{~s}^{-1}$ of light intensity produced biomass concentration of $1.77 \mathrm{~g} \cdot \mathrm{l}^{-1}$ with $21.6 \%$ of hydrocarbons. The qualitative and quantitative identification of hydrocarbon constituents generated was performed by external standard in gas chromatography. Calibration curves were composed of hydrocarbons from 5 at 32 carbons chain.
\end{abstract}

\section{Introduction}

The microalgae, Botryococcus braunii has the ability to synthesize and accumulate lipids and apolar substances, including hydrocarbons that can be used as an alternative of fossil fuels, if cost-effective technologies are employed [Lupi, et al., 1994; An JY et al., 2003; Aravantinou AF et al., 2013].Despite these benefits, the implementation of microalgal growth is actually reduced, requiring a domestication process to improve the culture conditions for increasing the biomass and hydrocarbon production, to obtain easily usable industrial bioprocess [Tran H-L et al., 2010; Cassedevall et al., 1985].

The growth of $\mathrm{B}$. braunii requires light, water, $\mathrm{CO}_{2}$ and inorganic nutrients, which are key factors to develop sustainable process in largescale. Therefore, the productivity is a function of different factors, such as $\mathrm{pH}, \mathrm{CO}_{2}$ concentration, light irradiation, salinity and temperature. It was reported that B. braunii converted $3 \%$ of incident solar energy into hydrocarbons, fixing atmospheric $\mathrm{CO}_{2}$. It was also estimated that about 183 tons of $\mathrm{CO}_{2}$ can be captured when 100 tons of microalgae biomass is produced, therefore, burning microalgae hydrocarbons does not significantly contribute to atmospheric $\mathrm{CO}_{2}$ accumulation, and is hence considered a green process[Razeghifard, 2013; Banerjee et al.,2002]. The marine phytoplankton is considered to be the most efficient photosynthetic carbon fixer on earth, but at a smaller scale, the freshwater microalgae also play a similar role in carbon cycle [Ramaraj et al.,2014]. The secondary treated wastewater used in this study possessed $887 \mathrm{ppm}$ dissolved $\mathrm{CO}_{2}$ that photosynthetic organisms could use as alternative carbon source.

Microalgae are potentially sustainable source for biofuel production as feedstock and do not compete with food, which could help to reduce the dependence of fossil fuels. The new studies tried to reduce the production costs and increase the biomass yield. For this, it is necessary to improve the research efforts to test efficient culture media and develop bioreactors at large scale [Lupi, et al., 1994; Pereira et al.,2012].

The production of hydrocarbon biofuel as alternative to fossil fuels need sustainable low cost process using less expensive raw materials, such as domestic or industrial effluents. These effluents comprise nutrients, bringing advantages, such as low cost production in microalgae production, for different purposes, including biodiesel and lipids production [Banerjee et al., 2002; Sydney et al., 2011; Di Termini et al., 2011].

It has been demonstrated that microalgae enhance their neutral lipids content under stress conditions, such as nutrient starvation, however, this increase is often coupled with biomass decrease [Bertozzini et al., 2011]. Some attempts to assemble a continuous process for the production of biomass have been developed using wastewater as growth medium.

* Corresponding Author: soccolu.@upfr.br 
Microalgae cultivation has been long considered as an alternative to wastewater treatment, mainly due to their capacity to deplete available nitrogen, phosphorus and other nutrients from municipal wastewater, which are exigent for the tertiary wastewater treatment process [Unnithan \& Smith, 2014; Dickinson et al., 2013].

The aim of this work was the use of secondary treated wastewater as culture media for $B$. braunii supplemented by an optimization study to determine the optimal salt concentrations [sodium nitrate, ferric citrate and dipotassium phosphate), $\mathrm{CO}_{2}$ (carbon dioxide) concentration and light intensity, for the production of biomass and hydrocarbons. As the secondary treated wastewater used in this work come from an anaerobic process, the characterization shows that it has low concentration of some nutrients that are important for microalgae. Despite of this feature generated daily volume makes it attractive for use in the massive cultivation of economically interesting microalgae

\section{Materials and Methods}

\subsection{Microorganisms}

The strains tested were: B. braunii (Utex LB 572) obtained from the UTEX, the Culture Collection of Algae, University of Texas, USA and $B$. braunii (CCAP 807/2) obtained from the Culture Collection of Algae and Protozoa, UK. Stock cultures were maintained in agar slants and in liquid cultures of $\mathrm{BG}_{11}$ medium with regular sub culturing. B. braunii (CCAP 807/2) was used in this study (screening data not shown).

\subsection{Culture conditions}

The secondary treated domestic wastewater (digested sewage) was provided by the Sanitation Company of Paraná SANEPAR, Curitiba, Brazil. The digested sewage used was initially treated anaerobically by the action of microorganisms in the absence of air or elemental oxygen, conducted in the Up flow Anaerobic Sludge Reactor operating in Curitiba - Brazil [Leitão et al., 2006]. This was collected at ETE South Atuba Station which is the largest anaerobic wastewater treatment plant of Paraná and benefit around 580,000 inhabitants of 14 districts of Curitiba, with a current capacity of treatment of $1,860 \mathrm{~L} \cdot \mathrm{s}^{-1}$. This digested sewage contains less biodegradable carbon and lower concentration of inorganic nutrients as nitrogen and phosphorous [Chemicharo et al., 2015]. The synthetic media for $B$. braunii growth, salts and quantities were the medium $\mathrm{CHU}_{13}$ [Largeou et al., 1980], $\mathrm{BG}_{11}$ [Tran H-L et al., 2010; Dayananda et al., 2007], and the medium 3N-BBM [Sydney et al., 2011].

\subsection{Secondary treated wastewater (Digested sewage)}

\subsubsection{Preparation}

The secondary treated wastewater was collected and transported to the Laboratory of Bioprocess Engineering at Federal University of Paraná. It was sterilized in autoclave at $121^{\circ} \mathrm{C}$ for $15 \mathrm{~min}$, cooled and stored at $20^{\circ} \mathrm{C}$.

\subsubsection{Secondary treated wastewater chemical analysis}

The composition of ions in the treated wastewater was determined using a 761 Compact IC 817 Bioscan chromatograph [APHA, 1995]. Column for anions determination: METROSEP A Supp 5 250/4.0 (Metrohm], $250 \mathrm{ml} \times 4.0 \mathrm{~mm}$ ID. Analytical conditions used were as follows: as mobile phase $1.0 \mathrm{mM} \mathrm{NaHCO}$ and $3.2 \mathrm{mM} \mathrm{Na}_{2} \mathrm{CO}_{3}, 0.7 \mathrm{~mL}$ $\mathrm{min}^{-1}$, room temperature of $25^{\circ} \mathrm{C}$, injected volume $20 \mu \mathrm{L}$. A standard curve was prepared for the following anions $\left(\mathrm{F}^{-1}, \mathrm{Cl}^{-1}, \mathrm{Br}^{-1}, \mathrm{NO}_{3}^{-1}, \mathrm{PO}^{-3}\right.$, $\mathrm{SO}_{4}^{-2}$ ). Column for cations determination: METROSEP C3 250/4.0 (Metrohm), $250 \mathrm{ml} \times 4.0 \mathrm{~mm}$ ID. Analytical conditions: as mobile phase $3.5 \mathrm{mM} \mathrm{HNO}_{3}, 0.9 \mathrm{~mL} \mathrm{~min}^{-1}, 40{ }^{\circ} \mathrm{C}$, injection volume $20 \mu \mathrm{L}$. A standard curve was prepared for the following cations $\left(\mathrm{Na}^{+}, \mathrm{NH}_{4}^{+}, \mathrm{K}^{+}, \mathrm{Mg}^{+2}, \mathrm{Ca}^{+2}\right)$.

\subsubsection{Analysis for Identification of Hydrocarbons}

The composition of hydrocarbons was determined using a Shimadzu chromatograph. Total Hydrocarbons (TH) was extracted from biomass using $n$-Heptane, Chloroform and Methanol. Briefly, $100 \mathrm{mg}$ of dried biomass were dissolved in $1 \mathrm{~mL}$ of $n$-heptane or chloroform/methanol (Mallinckrodt Chemicals, Saint Louis, MO, U.S.A.) and was determined by gas chromatography-flame ionization detection (GC-FID) and gas chromatography-Mass spectrometry detection (CG-MS). GC analysis was performed using a Shimadzu GC 14B gas chromatography equipped with a flame ionization detector (FID) (Shimadzu Co., Kyoto, Japan) and Shimadzu MSQP 2010 SE a DB-23 capillary column $(60 \mathrm{~m} \times 0.25$ $\mathrm{mm} \times 0.25 \mathrm{im})(\mathrm{J} \& W$ Scientific, Agilent Technologies, Santa Clara, CA, U.S.A). All parameters used for the GC run, described below, were optimized during this study. The injector and detector temperatures were 235 and $260^{\circ} \mathrm{C}$, respectively. Inlet pressure was $250 \mathrm{kPa}$, linear gas velocity was $14.5 \mathrm{~m} . \mathrm{s}^{-1}$ and split ratio was $1: 63$. Nitrogen was used as a carrier gas at a flow rate of $0.71 \mathrm{~mL} / \mathrm{min}$, with injection volumes of $1 \mu \mathrm{L}$ and $2 \mu \mathrm{L}$. Baseline separation was achieved at an oven temperature of $220{ }^{\circ} \mathrm{C}$ and running time of $11 \mathrm{~min}$. A standard curve was prepared for the following Hydrocarbon test Mix (cod. No. 48244, 47101, 47102, 47100) obtained from Sigma-Aldrich.The CG-FID chromatographic retention data was used being with support MS data, providing an independent parameter on which to base compounds identity. The reproducibility and reliability of retention indices allows assignment of identity to unknown components with greater confidence. The GC-MS analyses and the GC-FID quantitative analyses in the present investigation were all performed using the same column and instrumental conditions.

\subsubsection{Biomass Production}

Samples were collected from each experiment at 15,25 and 36 days. The biomass was removed by centrifugation in a centrifuge Sorvall Legend Mach $1.6 \mathrm{R}$ at $3465 x \mathrm{~g}$ for $15 \mathrm{~min}$ at $10^{\circ} \mathrm{C}$. Later, the sample was washed with distilled water, centrifuged and dried at $60^{\circ} \mathrm{C}$, until constant weight. Dry weight of microalgal biomass was determined gravimetrically and expressed as concentration of dry biomass per liter of medium $\left(\mathrm{g} \cdot \mathrm{l}^{-1}\right)$. The dried biomass was analyzed to determine the hydrocarbons production.

\subsection{Hydrocarbon extraction}

\subsubsection{External hydrocarbons extraction}

The dried biomass of $B$. braunii was extracted with hexane at room temperature for 1 hour and the process was performed in duplicates using a mass: volume ratio of 1:25. [Achitouv et al., 2004]

After the hydrocarbons extraction, the biomass was separated from the solvent phase by centrifugation at $3465 x \mathrm{~g}$ for $15 \mathrm{~min}$. The extracted fractions were mixed and concentrated under vacuum at $40{ }^{\circ} \mathrm{C}$. The amount of external hydrocarbons was gravimetrically obtained and expressed in percentage (\%) grams of dry hydrocarbons per grams of dry biomass x 100 .

\subsubsection{Internal hydrocarbons extraction}

In the sequence, the dried biomass of B. braunii extracted with hexane, was used for the extraction of internal hydrocarbons. The extraction was performed according to Folch method [Gritti et al., 2012]. Cells were lysed by adding a mixture of chloroform and methanol $(2: 1, \mathrm{v} / \mathrm{v})$ at the proportion of 20 times the amount of the sample $(20 \mathrm{ml}$ of solvent for 1 $\mathrm{g}$ of biomass). The suspension was stirred for $20 \mathrm{~min}$ at room temperature in a shaker.

The lower chloroform phase containing the hydrocarbons or weakly polar compounds was evaporated under vacuum in a rotary evaporator The extract was centrifuged to recover the liquid phase; it was washed with a solution of $\mathrm{NaCl} 0.9 \%(\mathrm{~m} / \mathrm{v})(4 \mathrm{~mL}$ to $20 \mathrm{~mL}$ of extract). After vortexing for one minute, the extract was centrifuged at low speed 554.5 $x \mathrm{~g}$ to separate the two phases. The aqueous phase containing polar molecules was removed with pipet. The organic phase, contains hydrocarbons was concentrated in a vacuum oven at $40^{\circ} \mathrm{C}$. The amount of internal hydrocarbons was obtained gravimetrically and expressed as a percentage (\%), grams of dry hydrocarbons per grams of dry biomass $\mathrm{x}$ 100 .

\subsection{Statistical analysis}

\subsubsection{Amount of Secondary Treated Wastewater for the media composition}

The experiment was performed in $250 \mathrm{~mL}$ flasks with a medium volume of $50 \mathrm{~mL}$, inoculums concentration of $0.1 \mathrm{~g} \cdot \mathrm{L}^{-1}$, temperature of $25 \pm 1^{\circ} \mathrm{C}$ and photoperiod of $12 \mathrm{~h}: 12 \mathrm{~h}$, in shaker (TECNAL, Model: TE-1401). The agitation was fixed at $100 \mathrm{rpm}$. A single factorial design was conducted for 15 days. The effects of five dilutions of secondary treated wastewater were evaluated, performed in 5 levels $(0,25,50,75$ and $100 \% \mathrm{v} / \mathrm{v}$ ) of secondary treated wastewater diluted in modified $\mathrm{BG}_{11}$. The results were analyzed using one way ANOVA procedure.

\subsubsection{Optimization of the culture medium}

The optimization of $B$. braunii biomass and hydrocarbon production was performed for 15 days, in $250 \mathrm{ml}$ flasks, working volume of $50 \mathrm{ml}$, inoculums of $0.1 \mathrm{~g} \cdot \mathrm{L}^{-1}$. The medium and flasks were sterilized in autoclave for $15 \mathrm{~min}$ at $121^{\circ} \mathrm{C}$. Growth was conducted in a shaker $100 \mathrm{rpm}$ (TECNAL, Model: TE-1401. Brazil), cells were grown at $25^{\circ} \mathrm{C} \pm 1^{\circ} \mathrm{C}$ under cool-white fluorescent illumination, $45 \mu \mathrm{mol}$ photons $\mathrm{m}^{-2} \mathrm{~s}^{-1}$ light 
intensity with $12: 12$ photoperiod hours.

The influence of three substances was studied $\left(\mathrm{NaNO}_{3}, \mathrm{~K}_{2} \mathrm{HPO}_{4}\right.$ and ferric ammonium citrate), using a DCCR design with 16 runs and 1 central point, to evaluated the interaction between the three salts at the biomass production, internal and external hydrocarbon accumulation. The effect of each factor was evaluated using STATISTICA 7 (Stat Soft 1984-2004, USA) statistical software. The other nutrients necessary for the growth of microalgae were added according to the $\mathrm{BG}_{11}$ media formulation.

\subsubsection{Influence of $\mathrm{CO}_{2}$ concentration and light intensity}

The experiments were performed for 25 days in a $6 \mathrm{~L}$ Erlenmeyer, using a volume of $3 \mathrm{~L}$. The culture medium was $50 \%(\mathrm{v} / \mathrm{v})$ treated wastewater and $50 \%$ medium $\mathrm{BG}_{11}$ modified (optimized concentrations of salts), inoculum of $0.2 \mathrm{~g}$ of biomass $\cdot \mathrm{L}^{-1}$, aeration 0.5 air volume per medium volume per minute (vvm), temperature $25^{\circ} \mathrm{C} \pm 1^{\circ} \mathrm{C}$, and photoperiod of 16:8 h light dark cycle.

A full factorial experimental design of two factors in two levels was employed, with a triplicate in central point for a total of seven experiments.

Light irradiance of $12.6,49$ and $70 \mu \mathrm{mol} . \mathrm{m}^{-2} \cdot \mathrm{s}^{-1}$ was tested. For $\mathrm{CO}$ influence as a culture condition, the three following concentrations were evaluated: 0,50 and $100 \mu \mathrm{L} \mathrm{L}^{-1} \cdot \mathrm{min}^{-1}$, the inlet of air and $\mathrm{CO}_{2}$ were independent in the photobioreactor. The $\mathrm{CO}_{2}$ was injected every two hours during the daylight hours of the photoperiod. The effect of the $\mathrm{CO}_{2}$ influence was evaluated in STATISTICA 7 (StatSoft 1984-2004, USA) statistical software.

\subsection{Scale up in Photo-bioreactor}

The scale up was performed at the optimal conditions determined. A photo-bioreactor New Brunswick Bioreactor illuminated with cool white $32 \mathrm{~W}$ fluorescent lamps was used. The $\mathrm{CO}_{2}$ injection was performed as described earlier. The whole experiment was carried out over 36 day of duration, the biomass and hydrocarbon was measured on day 24 . The photobioreactor conditions for validation and optimization of the operating and the main bio characteristics at $B$. braunii growing in the reactor were:volume of 9 Liters, temperature of $25{ }^{\circ} \mathrm{C}$, agitation at $100 \mathrm{rpm}$, aeration at $0.5 \mathrm{vvm}$, photoperiod between $16 \mathrm{~h}: 8 \mathrm{~h}$, irradiance approx. 70 $\mu \mathrm{mol}_{*} \mathrm{~m}^{-2}{ }_{*} \mathrm{~s}^{-1}$, gas $\mathrm{CO}_{2}$ concentration $33.33 \mathrm{ml}_{*} \mathrm{~L}^{-1}{ }_{*} \mathrm{~min}^{-1}$, Microorganism Botryococcus braunii (CCAP 807/2), Inoculum rate $0.2 \mathrm{~g}$ of biomass $\mathrm{L}^{-1}$, culture media of $50 \%$ treated wastewater and $50 \%$ BG11 modified.

\section{Results and Discussion}

\subsection{Secondary treated wastewater (digested sewage) analysis}

The characterization of secondary treated wastewater in terms of ion composition is presented in Table 1 . The average turbidity of the feedstock was $50 \mathrm{NTU}$, which did not affect light penetration at $680 \mathrm{~nm}$ in the photo-bioreactor; the $\mathrm{CO}_{2}$ concentration was $887 \mathrm{ppm}$, DQO of 59-17 $\mathrm{mg} \cdot \mathrm{O}_{2} \mathrm{~L}^{-1}$, and $\mathrm{DBO}_{5} 12.2 \mathrm{mg} \cdot \mathrm{O}_{2} \mathrm{~L}^{-1}$.

Table 1 presents a comparison of synthetic culture media recommended in the literature with digested sewage [Banerjee et al.,2002; Sydney et al., 2011; Dayananda et al., 2007]. Concentrations of calcium and chloride are higher in secondary treated wastewater than in the synthetic media. Magnesium and sulfate concentrations are similar in synthetic media and in the secondary treated wastewater; the concentrations of phosphate and nitrate are lower in treated wastewater.

Table 1. Composition of nutrients of synthetic media and secondary treated wastewater

\begin{tabular}{|c|c|c|c|c|}
\hline Parameter & $\begin{array}{c}\text { Treated } \\
\text { Wastewater } \\
(\mathrm{ppm})\end{array}$ & $\begin{array}{c}\mathrm{BG}_{11} \\
\text { modified } \\
(\mathrm{ppm})\end{array}$ & $\underset{\text { modified }}{\mathrm{CHU}_{13}}$ & $\begin{array}{c}3 N- \\
\text { BBM } \\
(\text { ppm) }\end{array}$ \\
\hline Ammonia & 19.54 & - & & - \\
\hline Calcium & 33.58 & 1.12 & 15.83 & 7.76 \\
\hline Chloride & 49.08 & 0.99 & 14.03 & 6.88 \\
\hline Magnesium & 8.81 & 7.40 & 9.87 & 7.40 \\
\hline Nitrate & 28.28 & 364.71 & 122.77 & 547.06 \\
\hline Phosphate & 1.03 & 16.67 & 16.67 & 154.40 \\
\hline Potassium & 10.88 & 6.84 & 84.07 & 63.38 \\
\hline Sodium & 23.19 & 141.01 & 0.00 & 212.78 \\
\hline Sulfate & 22.97 & 29.23 & 38.98 & 29.23 \\
\hline $\mathrm{pH}$ & 6.70 & 7.40 & 7.50 & 6.20 \\
\hline
\end{tabular}

Nitrate concentration lower than $200 \mathrm{ppm}$ improves the production of hydrocarbons, however, concentrations higher than $1,000 \mathrm{ppm}$ interferes with the hydrocarbon production [Banerjee et a.,2002]. This result encourages the use of secondary treated wastewater as alternative medium for microalgae growth, as some other authors have already proven Osundeko et al. (2013) showed that the Chlorella luteoviridis and Parachlorella hussii, could grow adequately in raw wastewater due to their substantial tolerance to oxidative stress, highly induced by the wastewater environment [Osundeko et al., 2013]. Phosphorus is necessary for the growth of $B$. braunii and the growth medium are usually supplemented with salts, such as $\mathrm{K}_{2} \mathrm{HPO}_{4}$. The active growth persists, until the complete consumption of phosphate in the medium [Kassim \&.Meng, 2017].

Another important factor is the ammonium concentration, when cells are exposed to $5 \mathrm{mM} \mathrm{NH}_{4}^{+}$for 24 hours, the nitrate reductase enzyme is inactivated and this is detrimental to cells [Banerjee et al.,2002]. The toxicity caused by $\mathrm{NH}_{4}{ }^{+}$is expressed during late exponential phase and the damage caused is irreversible [Lupi et al., 1994, Banerjee et al.,2002]. For this reason, the ammonium concentration in the culture media must be near zero; the secondary treated wastewater has a concentration of 1 $\mathrm{mM}$ of $\mathrm{NH}_{4}^{+}$, but this amount does not significantly affect the development B. braunii.

\subsection{Statistical analysis}

\subsubsection{Concentration of secondary treated wastewater}

The one-way ANOVA results with a statistical significance of $95 \%$ (p value: 0.05 ), showed that no significant difference existed between the different tested secondary treated wastewater percentages (the $p$ value obtained 0.3857 ). As seen in Figure 1, the biomass concentration of each treatment is almost constant for the overall concentration of secondary treated wastewater. In order to promote adaptationof $B$. braunii cells to the secondary treated wastewater as an alternative medium, $50 \% \mathrm{v} / \mathrm{v}$ was chosen to continue with the following experiments, based on microscopic analysis of the cells, evaluating shape and culture color.

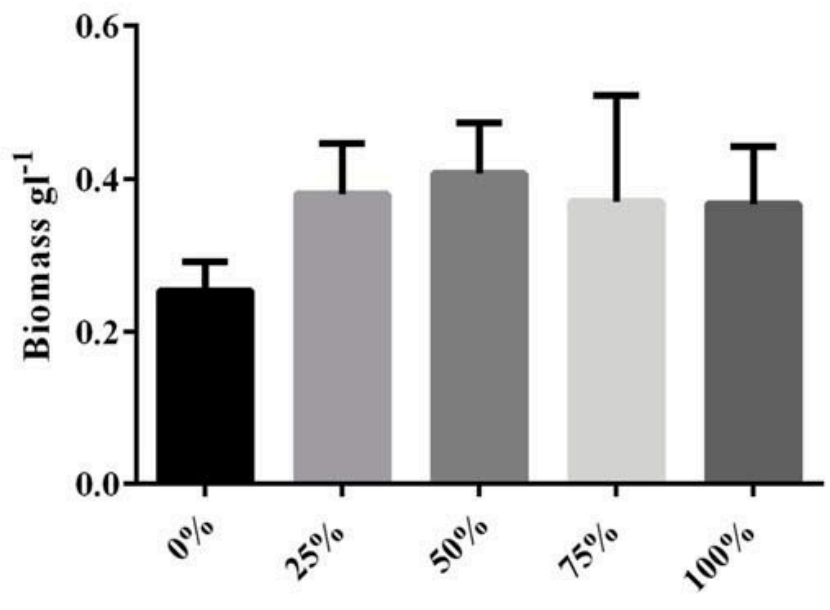

$\%$ Secondary treated wastewater $\mathrm{v} / \mathrm{v}$

Figure 1. B. braunii biomass production $\left(\mathrm{g} \cdot \mathrm{L}^{-1}\right)$ with different percentage of secondary treated wastewater

\subsubsection{Salt concentration optimization}

Based on the literature [Tran H-L et al., 2010; Banerjee et al.,2002], and previous experiments, sodium nitrate, ferric citrate and potassium phosphate were chosen as the salts to be studied. Table 2 presents the DCCR and the response variables. With a significance level of $90 \%(\mathrm{p}$ value $<0.1$ ), from the statistical analysis, it was found that the potassium phosphate and ferric citrate were statistically representative that influenced the $B$. braunii biomass growth. The optimal concentration of the three salts determined was $0.3 \mathrm{~g} \cdot \mathrm{L}^{-1}$ of sodium nitrate, $0.018 \mathrm{~g} \cdot \mathrm{L}^{-1}$ of ferric citrate and $0.12 \mathrm{~g} \cdot \mathrm{L}^{-1}$ of potassium phosphate for the production of biomass and hydrocarbons accumulation.

Figure 2(a) presents the Pareto chart and Figure 2(b) shows the surface response for biomass production as a function of the salts concentration (ferric citrate and potassium phosphate). From the results, it was determined 
Table 2. Central composite design for inorganic salts concentration evaluation for $B$. braunii biomass and hydrocarbon production

\begin{tabular}{|c|c|c|c|c|c|c|c|c|c|}
\hline \multirow[t]{2}{*}{ Run } & \multicolumn{2}{|c|}{$\mathrm{NaNO}_{3}$} & \multicolumn{2}{|c|}{$\mathrm{K}_{2} \mathrm{HPO}_{4}$} & \multicolumn{2}{|c|}{ Ferric Citrate } & \multirow{2}{*}{$\begin{array}{c}\text { Biomass } \\
\mathrm{g} \cdot \mathrm{L}^{-1}\end{array}$} & \multirow{2}{*}{$\begin{array}{c}\text { external HC } \\
\%\end{array}$} & \multirow{2}{*}{$\begin{array}{c}\text { internal } \mathrm{HC} \\
\%\end{array}$} \\
\hline & Code & $\mathrm{g} \cdot \mathrm{L}^{-1}$ & Code & $\mathrm{g} \cdot \mathrm{L}^{-1}$ & Code & $\mathrm{g} \cdot \mathrm{L}^{-1}$ & & & \\
\hline 1 & -1 & 0.200 & -1 & 0.072 & -1 & 0.011 & 0.646 & 9.29 & 8.36 \\
\hline 2 & -1 & 0.200 & -1 & 0.072 & 1 & 0.025 & 0.726 & 4.41 & 7.99 \\
\hline 3 & -1 & 0.200 & 1 & 0.168 & -1 & 0.011 & 0.714 & 8.96 & 7.28 \\
\hline 4 & -1 & 0.200 & 1 & 0.168 & 1 & 0.025 & 0.666 & 3.90 & 7.21 \\
\hline 5 & 1 & 0.400 & -1 & 0.072 & -1 & 0.011 & 0.568 & 2.46 & 9.15 \\
\hline 6 & 1 & 0.400 & -1 & 0.072 & 1 & 0.025 & 0.592 & 2.03 & 7.77 \\
\hline 7 & 1 & 0.400 & 1 & 0.168 & -1 & 0.011 & 0.484 & 12.81 & 5.37 \\
\hline 8 & 1 & 0.400 & 1 & 0.072 & 1 & 0.025 & 0.664 & 6.02 & 9.04 \\
\hline 9 & -1.68 & 0.100 & 0 & 0.120 & 0 & 0.018 & 0.962 & 11.23 & 5.82 \\
\hline 10 & 1.68 & 0.500 & 0 & 0.120 & 0 & 0.018 & 0.868 & 11.75 & 4.84 \\
\hline 11 & 0 & 0.300 & $-1,68$ & 0.040 & 0 & 0.018 & 0.564 & 7.09 & 9.22 \\
\hline 12 & 0 & 0.300 & 1,68 & 0.200 & 0 & 0.018 & 0.604 & 8.94 & 5.96 \\
\hline 13 & 0 & 0.300 & 0 & 0.120 & -1.68 & 0.006 & 0.960 & 9.79 & 5.62 \\
\hline 14 & 0 & 0.300 & 0 & 0.120 & 1.68 & 0.030 & 1.050 & 5.14 & 6.10 \\
\hline 15 & 0 & 0.300 & 0 & 0.120 & 0 & 0.018 & 0.674 & 6.82 & 7.12 \\
\hline 16 & 0 & 0.300 & 0 & 0.120 & 0 & 0.018 & 0.834 & 7.67 & 9.83 \\
\hline 17 & 0 & 0.300 & 0 & 0.120 & 0 & 0.018 & 0.670 & 1.49 & 8.96 \\
\hline
\end{tabular}

a

Pareto Chart of Standardized Effects; Vanable: Biomass 3 factors, 1 8locks, 17 Runs; US Pure Errorz, 0066987 DV: Biomass

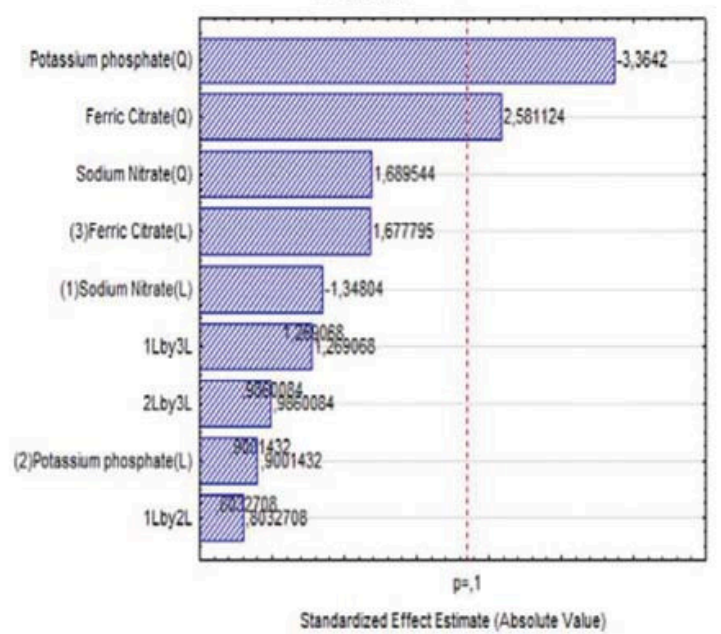

b

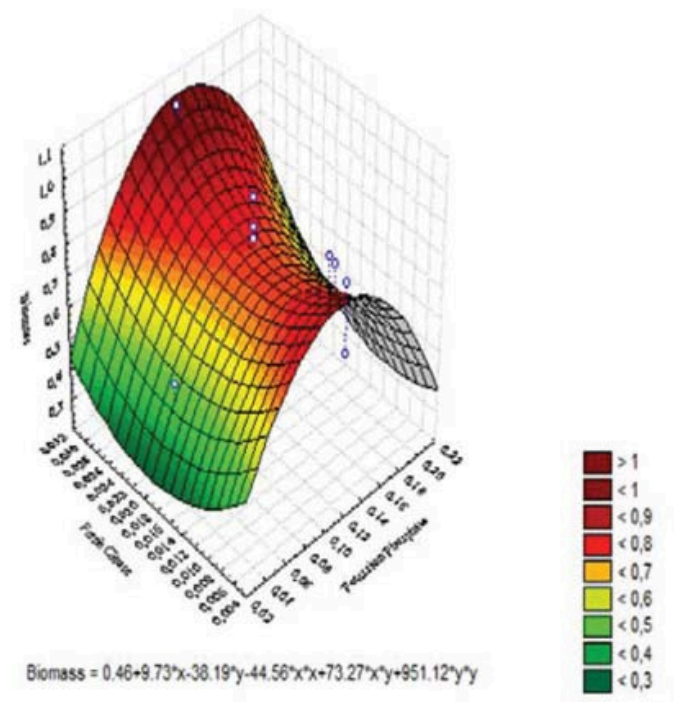

Figure 2. Central composite design results for biomass. (a) Pareto chart of standardized effects; and (b) Response surface plot for biomass as a function of potassium phosphate and ferric citrate

that the minimum concentration of ferric citrate and potassium phosphate for biomass production was 39 and $32 \mathrm{ppm}$, respectively.

The biomass productivity obtained prior to the optimization of salt concentration was $20.6 \mathrm{mg} \cdot \mathrm{L}^{-1} \cdot \mathrm{day}^{-1}$. After optimization, the production of biomass increased three times, reaching $63.3 \mathrm{mg} \cdot \mathrm{L}^{-1} \cdot \mathrm{day}^{-1}$, this productivity is good enough for 15 days, for some other authors attain the following biomass productivity evaluating different culture medium and optimizing other parameters from the culture conditions of the same microalgae. After proving with different medium, photoperiod and shaking in 6 weeks Dayananda et al. (2007) produced $47.6 \mathrm{mg} \cdot \mathrm{L}^{-1} \cdot \mathrm{day}^{-1}$ of $B$. braunii biomass, for other study of $\mathrm{pH}$ and carbon dioxide for a period of 3 weeks produced $40.9 \mathrm{mg} \cdot \mathrm{L}^{-1} \cdot \mathrm{day}^{-1}$ of $\mathrm{B}$. braunii.

Figure 3(a) shows the Pareto chart and Figure 3(b) presents the response surface of internal hydrocarbons as a function of sodium nitrate and potassium phosphate. Internal hydrocarbons were obtained in lower quantity compared with external hydrocarbons, due to their dynamics in the growth kinetics of B. braunii. Achitouv (2004) obtained 3.6\% of internal hydrocarbons while the external hydrocarbons $13.2 \%$ of the biomass. As the extraction of the hydrocarbons was performed at the early stationary phase, more external hydrocarbons were accumulated than internal hydrocarbons, this is a normal process reported by other authors as well. In the best result of this experiment $11.23 \%$ of external hydrocarbons were obtained and $5.82 \%$ of internal hydrocarbons .

Pareto chart presented in Figure 4(a) and the response surface in Figure 4(b) showed the influence of parameters on the external hydrocarbons. For a $90 \%$ of significance level, the external hydrocarbons were not influenced by the concentration and variation of salt. .

External hydrocarbons produced by B. braunii, such as botryococcenes, methylated squalenes and long chain triterpenes [Metzger \& Largeau, 2005] were accumulated in the stationary phase of growth, when most of the nutrients are depleted; so that very small amounts of the salts are required for hydrocarbons accumulation.

B. braunii strain A produces alkadien and trien as external hydrocarbons [Banerjee et al.,2002]. Also, some studies proved that this strain is a rich source of lipids, including fatty acids, epoxides, alkyl phenols, and lipid ethers as internal hydrocarbons [Achitouv et.al., 2004]. Some of the internal hydrocarbons, such as oleic acid are direct precursors of external hydrocarbons, such asn-alkadienes. The intracellular concentration of oleic acid remained relatively low during rapid production of external hydrocarbons [Banerjee et al.,2002]. This explained the lower production of the internal hydrocarbons in comparison with the external hydrocarbons. 

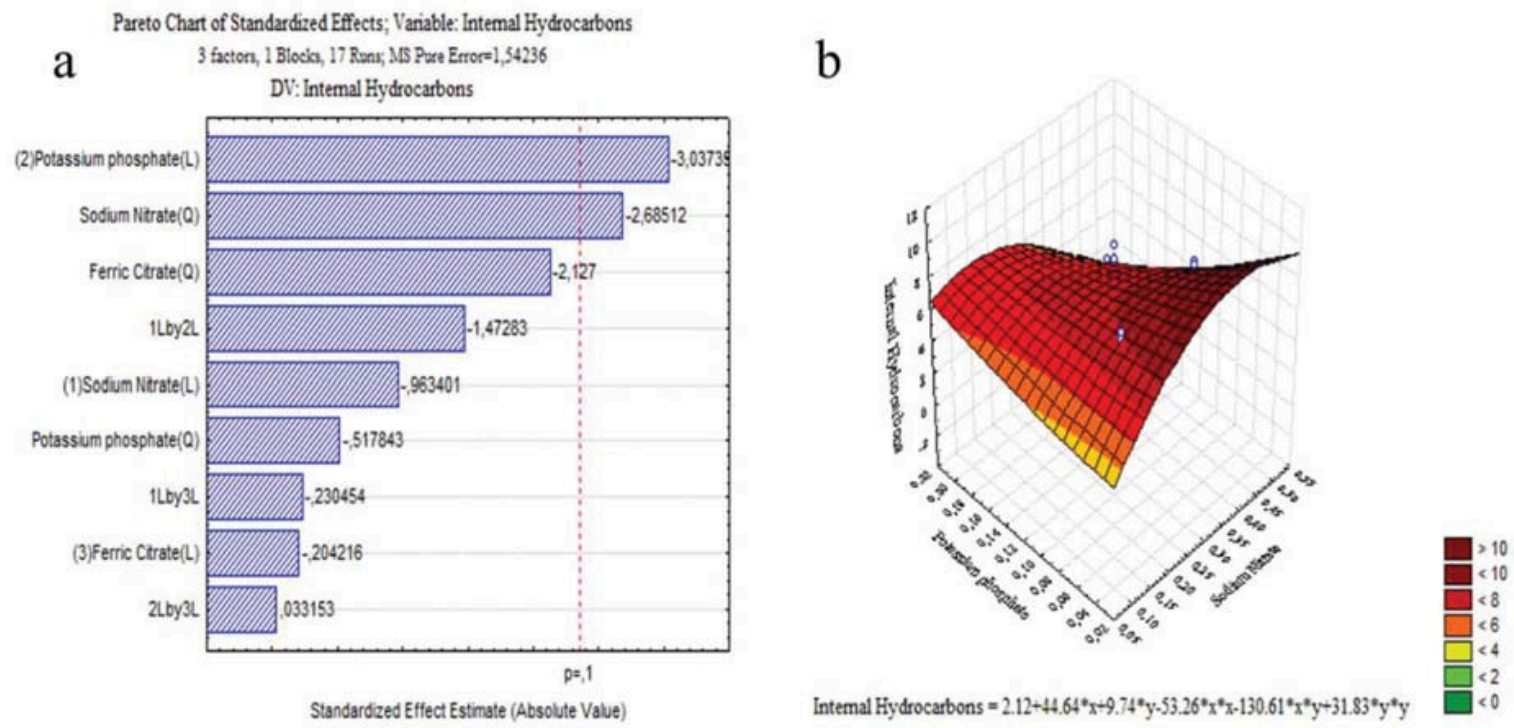

Figure 3. Central composite design results for internal hydrocarbons. (a) Pareto chart of standardized effects. (b) Response surface plot for internal hydrocarbons as a function of potassium phosphate and sodium nitrate
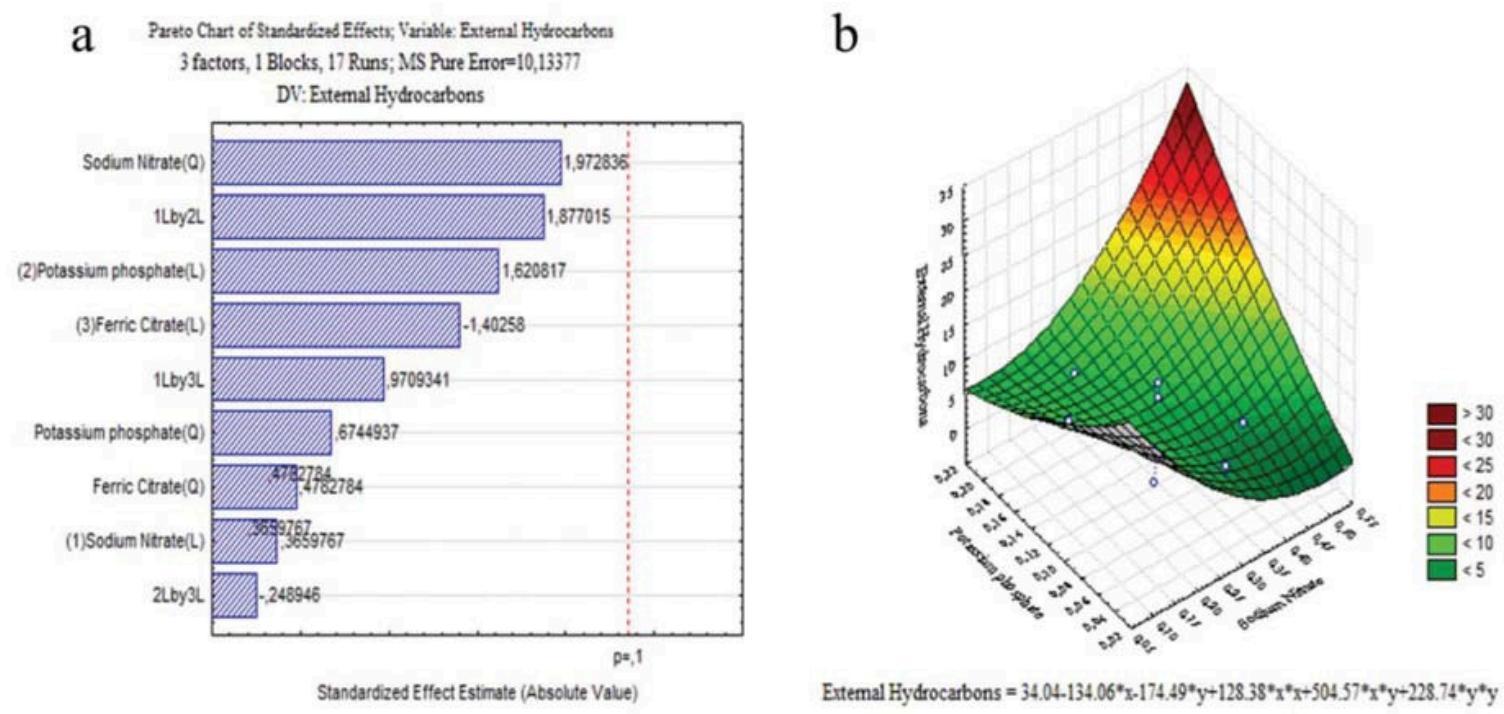

Extemal Hydrocarbons $=34.04-134.06^{*} x-174.49^{*} y+128.38^{*} x^{*} x+504.57 x^{*} x^{*} y+228.74^{*} y^{*} y$

Figure 4. Central composite design results for external hydrocarbons. (a) Pareto chart of standardized effects and; (b) Response surface plot for external hydrocarbons as a function of potassium phosphate and sodium nitrate

\subsubsection{Influence of $\mathrm{CO}_{2}$ concentration and light intensity}

The $\mathrm{CO}_{2}$ concentration and light intensity on the biomass production of microalgae $B$. braunii was studied using an experimental design of two factors with two levels, with triplicate in central point; and the experimental design is presented in Table 3. Biomass production and percentage of external and internal hydrocarbons were chosen as response variables. The hydrocarbons production is shown in Table 3.

With a significance of $90 \%$, the light incidence was the major factor, which influenced the biomass production of B.braunii ( $p$ value 0.0195).

Table 3. Box Hunter \& Hunter statistical design to evaluate $\mathrm{CO}_{2}$ and Light intensity in B.braunii culture

\begin{tabular}{|c|c|c|c|c|c|c|c|}
\hline \multirow[b]{2}{*}{ Run } & \multicolumn{2}{|c|}{$\mathrm{CO}_{2}$} & \multicolumn{2}{|c|}{ Light } & \multirow{2}{*}{$\begin{array}{r}\text { Biomass } \\
\left(\mathrm{g} \cdot \mathrm{L}^{-1}\right)\end{array}$} & \multirow{2}{*}{$\begin{array}{c}\text { External hydrocarbons } \\
(\%)\end{array}$} & \multirow{2}{*}{$\begin{array}{c}\text { Internal hydrocarbons } \\
(\%)\end{array}$} \\
\hline & Coded & $\left(\mathrm{ml} \mathrm{L}^{-1} \mathrm{~min}^{-1}\right)$ & Coded & $\left(\mathrm{mmol} \cdot \mathrm{m}^{-2} \cdot \mathrm{s}^{-1}\right)$ & & & \\
\hline $\begin{array}{l}(\mathrm{A}) \\
(\mathrm{B}) \\
(\mathrm{C}) \\
(\mathrm{D}) \\
(\mathrm{E}) \\
(\mathrm{F}) \\
(\mathrm{G})\end{array}$ & $\begin{array}{c}-1 \\
1 \\
-1 \\
1 \\
0 \\
0 \\
0\end{array}$ & $\begin{array}{c}0 \\
100 \\
0 \\
100 \\
50 \\
50 \\
50\end{array}$ & $\begin{array}{c}-1 \\
-1 \\
1 \\
1 \\
0 \\
0 \\
0\end{array}$ & $\begin{array}{c}12.6 \\
12.6 \\
70 \\
70 \\
49 \\
49 \\
49\end{array}$ & $\begin{array}{l}0.539 \\
0.519 \\
1.442 \\
1.772 \\
1.274 \\
0.838 \\
0.967\end{array}$ & $\begin{array}{c}10.2 \\
8.3 \\
17.1 \\
21.7 \\
11.1 \\
11.3 \\
15.5\end{array}$ & $\begin{array}{l}2.6 \\
2.7 \\
2.9 \\
1.4 \\
1.9 \\
2.7 \\
2.5\end{array}$ \\
\hline
\end{tabular}


The optimal light intensity was $70 \mathrm{~mol} \cdot \mathrm{m}^{-2} \mathrm{~s}^{-1}$ with a productivity of 63 $\mathrm{mg} \cdot \mathrm{L}^{-1} \mathrm{day}^{-1}$ of dry biomass, a yield of $21.6 \%$ of external hydrocarbons and internal hydrocarbons yield was $1.4 \%$. In this experiment external hydrocarbons were higher than internal, light incidence affected external hydrocarbon accumulation due to the bond between external hydrocarbons and biomass at the early stationary phase as described earlier. In some studies, other physical and chemical parameters were evaluated. Sydney et al. (2011) used the same strain for potential biofuel screening and at 14 days the biomass concentration was $0.48 \mathrm{~g} \mathrm{~L}^{-1}$, this means a productivity of $34.3 \mathrm{mg} \mathrm{L}-1 \mathrm{day}^{-1}$. Kassim and Meng (2017) study the $\mathrm{CO}_{2}$ biofixation by Chlorella sp. and Tetraselmis suecica with a biomass concentration of $0.64 \mathrm{~g} \mathrm{~L}^{-1}$ and $0.72 \mathrm{~g} \mathrm{~L}^{-1}$ respectively.

The cultivation of microalgae using artificial lighting at different intensities showed that the biomass concentration increased with the light intensity, without influencing the accumulation of internal hydrocarbons. The relation of the biomass production, internal hydrocarbons and external hydrocarbons accumulation with the light and $\mathrm{CO}_{2}$ concentration are depicted at Figure 5, a, b and c, by the Pareto charts of standardized effects.

The $\mathrm{CO}_{2}$ concentration levels proved to have no statistical significance on $B$. braunii biomass production or hydrocarbon accumulation even though $\mathrm{CO}_{2}$ is the microalgae carbon source and it is necessary for photosynthesis, also convert the dissolved carbon dioxide into organic cellular components (proteins, carbohydrates, lipids and nucleic acid) [Cabello, 2017]. It is known that microalgae operate a $\mathrm{CO}_{2}$ concentrating mechanism to overcome the poor $\mathrm{CO}_{2}$ affinity of the major carbon-fixing enzyme, ribulose-bisphosphate carboxylase/oxygenase. $\mathrm{CO}_{2}$ concentrating mechanism is most likely to be the molecular mechanism underlying the possible enhancement of microalgae carbon fixation efficiency during growth in carbon-limited environment [Ramaraj et al.,2014]. Cultivation of microalgae using $\mathrm{CO}_{2}$ not only affects its growth, but it could also affect microalgae metabolism and the chemical composition distribution in its biomass [Kassim \&Meng, 2017].

\subsection{Kinetics validation in photobioreactor}

Figure 6 presents the kinetics of biomass production during 36 days of $B$. braunii cultivation in a $9 \mathrm{~L}$ photobioreactor. During the validation, $1.88 \mathrm{~g} \cdot \mathrm{L}^{-1}$ of biomass was obtained; nitrate remained at a concentration below the detection value at $0.01 \mathrm{~g} \cdot \mathrm{L}^{-1}$ for the used method, described in the section 2.3.2. The removal of the nutrients was about $93.75 \%$.

The maximum cell concentration achieved $\left(\mathrm{X}_{\text {max }}\right)$ was $1.88 \mathrm{~g} \cdot \mathrm{L}^{-1}$. The specific growth rate $\left(\mu_{\max }\right)$ was 0.1 day $^{-1}$, determined during the exponential phase (5 to 15 days). The productivity $(\gamma)$ was $53 \mathrm{mg} \cdot \mathrm{L}^{-1} \mathrm{day}^{-1}$ and the biomass doubling time (Td) 6.93 days.

Franchino et al. (2016) used Chlorella vulgaris in anaerobic digestate obtaining a high removal efficiency (>90\%) for nitrogen, ammonia and phosphate, reducing the wastewater toxicity [29]. Other studies using microalgae showed that these microorganisms could be used as a tertiary treatment to decrease the treated wastewater salinity [Di Termini et al., 2011;Wu Y-H, 2013].

In other investigations Scenedesmus was evaluated for nitrogen and phosphorus removal from treated wastewater as well as biomass and lipid productivity, a nutrient removal of $99.9 \%$ was obtained and a biomass productivity of $0.25 \mathrm{~g} \cdot \mathrm{L}^{-1}$ [Di Termini et al., 2011]. In the work reported by AN Jiet al.(2013) Chlorella vulgaris, Scenedesmus obliquus and Ourococcus multisporus, were studied, as wastewater treatment and lipid production and there was complete removal ( $>99 \%)$ of nitrogen and phosphorus within 4 days. The highest specific lipid productivity was 0.164 g-lipids. g-cell-1 day- 1 for $C$. vulgaris after 7 days of cultivation in the presence of $\mathrm{CO} 2$, shown to be a potential source for biodiesel production and removal of nutrients from wastewate.
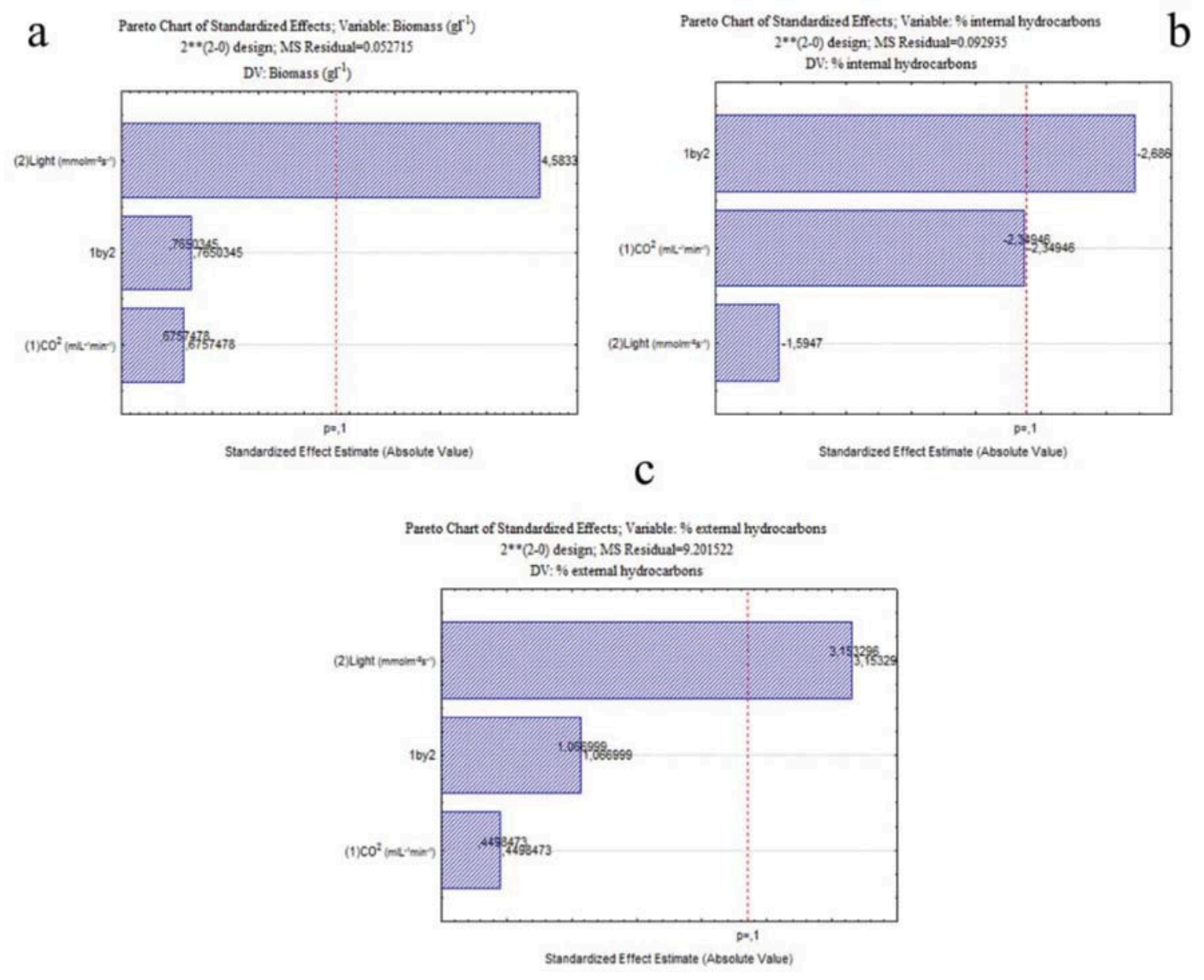

Figure 5. Pareto charts of standardized effects. (a) Variable biomass $g \cdot \mathrm{L}^{-1}$. (b) Percentage of internal hydrocarbons.

(c) Percentage of external hydrocarbons 


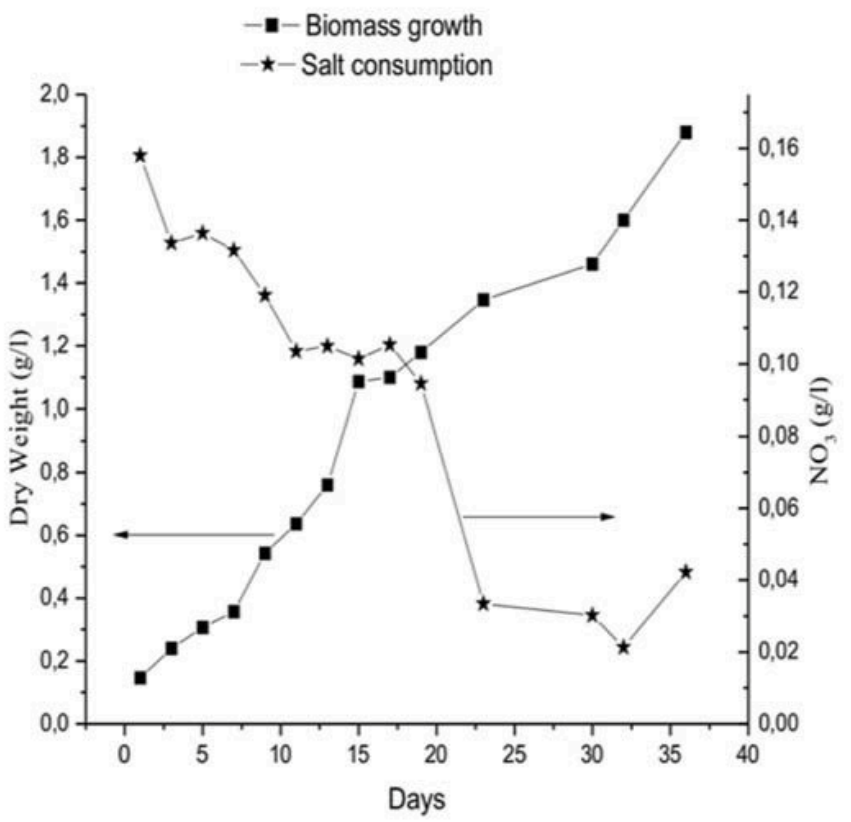

Figure 6. Growth kinetics of biomass $B$. braunii and consumption of $\mathrm{NO} 3$ for validation in photobioreactor.

During this study, the total percentage of hydrocarbons extracted after 24 days from the culture was $39.05 \%$ of dry biomass; $27.49 \%$ of dry biomass of external hydrocarbons and $11.59 \%$ of dry biomass of internal hydrocarbons. After 36 days of culturing, total hydrocarbons of $16.95 \%$ of dry biomass, external hydrocarbons $13.24 \%$ of dry biomass and internal hydrocarbons $3.71 \%$ of dry biomass were obtained, and they were within the range reported in the literature. The percentage of total hydrocarbons reduced along the time and a possible cause is the release of oil droplets
Table 4 - Total mass percentage of the internal and external content of hydrocarbons from $\mathrm{CO}_{2}$ and Light intensity experiment.

\begin{tabular}{c|c|c|c}
\hline \multicolumn{3}{|c|}{ Biomass } & Total Hydrocarbons \\
\hline Run & $\left(\mathrm{gL}^{-1}\right)$ & $(\mathrm{mg})^{*}$ & (\% relative from Biomass) \\
\hline (A) & 0.539 & 0.13 & 1.2 \\
(B) & 0.519 & 0.11 & 1.0 \\
(C) & 1.442 & 0.75 & 6.8 \\
(D) & 1.772 & 1.09 & 9.9 \\
(E) & 1.274 & 0.42 & 3.8 \\
(F) & 0.838 & 0.27 & 2.4 \\
(G) & 0.967 & 0.41 & 3.8 \\
\hline
\end{tabular}

*dry base

into the culture medium in the late stationary phase. Besides, many cells are lysed due to cell death releasing the hydrocarbons which can hinder their full recovery, this phenomena was observed in the microscopy that presents $B$. braunii cells at different growth phases: exponential growth phase ( $5^{\text {th }}$ day) where cells remained intact and green; early stationary phase: oil drops can be seen inside the cells ( $24^{\text {th }}$ day), during this phase, the oils can be directly extracted from the biomass collected; late stationary phase: oil droplets are released to the liquid media by this period $\left(30^{\text {th }}\right.$ day), becoming more difficult to recover by conventional methods, like filtration or centrifugation. Thus, it is recommended to collect cells after 25 days of culturing.

The novelty of this work was the study with $B$. braunii that not only produces lipids, but also hydrocarbons, being an alternative source of biofuels. The results obtained in the study, using $50 \% \mathrm{v} / \mathrm{v}$ of secondary treated wastewater (digested sewage) as growth medium, and the optimized $B$. braunii growth conditions showed that this is a suitable medium for biofuel production using microalgal hydrocarbons.

\subsection{Hydrocarbons : external and internal composition in the dry biomass of $\mathrm{B}$. braunii}

The dried biomass of $B$. braunii extracted with hexane and a mixture of chloroform and methanol were analyzed. Figure 7 (A and B) shows

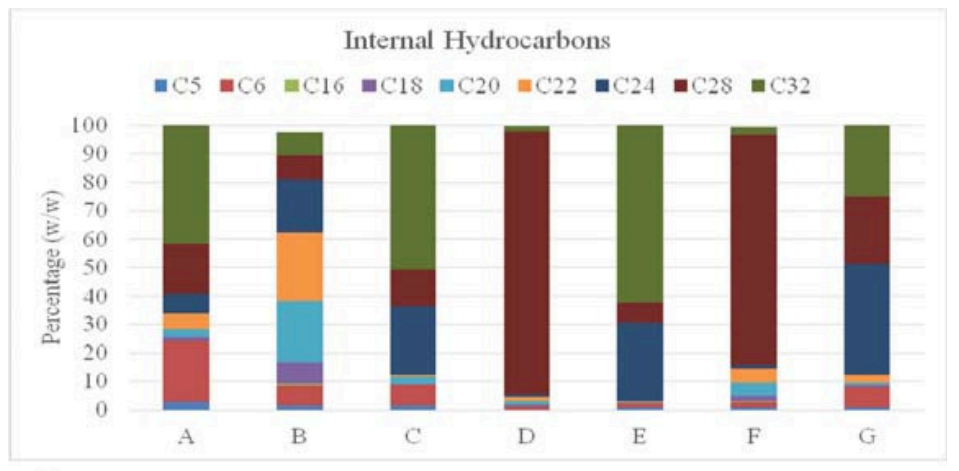

(a)

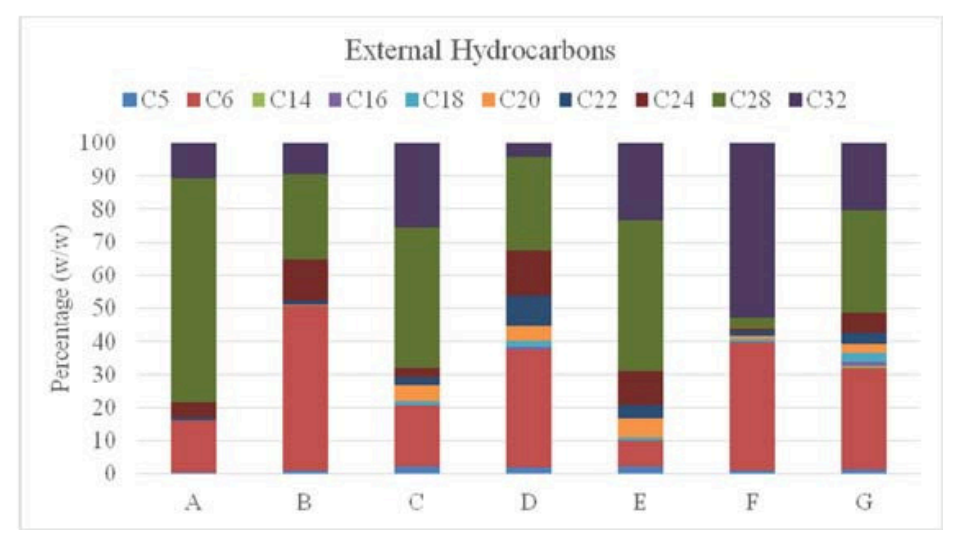

Figure 7. GC analysis for: a) Internal hydrocarbons and; b) External hydrocarbons. 
the result of non-polar components internal and external from the cells. The hydrocarbon constituent identification obtained for the treatments $\mathrm{A}$ to $\mathrm{G}$, was represented by different concentration and colors. Table 4 expressed total mass percentage for the internal and external content of hydrocarbons for each treatment.

For these samples, it was found to have components C5, C6, C18, C20, C22, C24, C28 and C32. For biomass and hydrocarbon production, $\mathrm{D}$ treatment was the best and the hydrocarbons present in this treatment were,approximately ten times more than treatment B that was the lowest producing this study. For internal hydrocarbons, C28 and C24 were the most abundant. For external hydrocarbons, C28, C6 and C32 were the most abundant. C32 is Botryococcene and other authors also found this kind of hydrocarbons in fraction extracted with heptane [Achitouv et al., 2004]. The treatments that received $70 \mathrm{mmolm}^{-2} \cdot \mathrm{s}^{-1}$ of light $(C$ and $D)$ accumulated more external hydrocarbons as described by Dayananda et al. (2007). Hydrocarbon content was higher under continuous light, but produced longer carbon chains in 16:8 h light:dark period.

\section{Conclusions}

The secondary treated wastewater (digested sewage) can be used as a source of nutrients for biomass production of $B$. braunii, reducing the cost of the hydrocarbon base biofuel production. The digested sewage is low cost and it can replace $50 \%(\mathrm{v} / \mathrm{v})$ of fresh water reaching biomass productivity between $53 \mathrm{mg} \cdot 1^{-1} \mathrm{day}^{-1}$ to $63 \mathrm{mg} \cdot 1^{-1} \mathrm{day}^{-1}$, representing approximately 1.2 to $1.8 \mathrm{~g} \cdot \mathrm{L}^{-1}$ of dry biomass in 15 to 30 days without causing toxicity, besides using $\mathrm{BG}_{11}$ complements nutrients. The culture of $B$. braunii for 25 days is recommended due to highest hydrocarbon accumulation, otherwise an important biomass increase was observed until the $35^{\text {th }}$ day. The composition of the internal non-polar compounds produced by $B$. braunii, was hydrocarbons with 24 and 28 carbons, and the external fraction was composed mostly of hydrocarbons with 6,28 and 32 carbons, thus possessing potential to be used as biofuel.

\section{References}

[1] Achitouv E., Metzger P., Rager M.N., Largeau C., 2004. C-31-C-34 methylated squalenes from a Bolivian strain of Botryococcus braunii. Phytochemistry, 65(23):3159-65.

[2] An J.Y., Sim S.J., Lee J.S., Kim B.W., 2003. Hydrocarbon production from secondarily treated piggery wastewater by the green alga Botryococcus braunii. Journal of Applied Phycology, 15(2-3):185-91.

[3] APHA, AWWA, WEF, 1995. Standard Methods for the Examinations of Water and Wastewater. Baltimore, Maryland: United Book Press, Inc.

[4] Aravantinou A.F., Theodorakopoulos M.A., Manariotis I.D., 2013, Selection of microalgae for wastewater treatment and potential lipids production. Bioresource Technology, 147(0):130-4.

[5] Banerjee A., Sharma R., Chisti Y., Banerjee U.C., 2002, Botryococcus braunii: A renewable source of hydrocarbons and other chemicals. Critical Reviews in Biotechnology, 22(3).

[6] Bertozzini E., Galluzzi L., Penna A., Magnani M., 2014. Enhancing neutral lipid content in Skeletonema marinoi through multiple phase grow th in a bench photobioreactor. Algal Research, 5(0):32-6.

[7] Cabello J., Morales M., Revah S., 2017. Carbon dioxide consumption of the microalga Scenedesmus obtusiusculus under transient inlet $\mathrm{CO}$ concentration variations. Science of The Total Environment.Apr 15:584-585, 1310-1316.

[8] Casadevall E., Dif D., Largeau C., Gud in C., Chaumont D., Desanti O., 1985. Studies on batch and continuous cultures of Botryococcus-braunii - hydrocarbon production in relation to physiological-state, cell ultrastructure, and phosphate nutrition. Biotechnology and Bioengineering, 27(3):286-95.

[9] Chernicharo, C.A.L., van Lier, J.B., Noyola ,A., Ribeiro, T.B., 2015. Anaerobic sewage treatment: state of the art, constraints and challenges. Reviews in
Environmental Science and Bio/Technology, December; 14 (4): 649-679.

[10] Dayananda C., Sarada R., Rani M.U., Shamala T.R., Ravishankar G.A., 2007. Autotrophic cultivation of Botryococcus braunii for the production of hydrocarbons and exopolysaccharides in various media. Biomass \& Bioenergy, 31(1):87-93.

[11] Di Termini I., Prassone A., Cattaneo C., Rovatti M., 2011. On the nitrogen and phosphorus removal in algal photobioreactors. Ecological Engineering, 37(6):976-80.

[12] Dickinson K.E., Whitney C.G., McGinn P.J., 2013. Nutrient remediation rates in municipal wastewater and their effect on biochemical composition of the microalga Scenedesmus sp. AMDD. Algal Research, 2(2):127-34.

[13] Franchino M., Tigini V., Varese G.C., Mussat Sartor R., Bona F., 2016.Microalgae treatment removes nutrients and reduces ecotoxicity of diluted piggery digestate. Science of The Total Environment, 569-570:40-5.

[14] Gritti F., Perdu M-A., Guiochon G., 2012. Gradient HPLC of samples extracted from the green microalga Botryococcus braunii using highly efficient columns packed with $2.6 \mathrm{mu} \mathrm{m}$ Kinetex-C-18 core shell particles. Journal of Chromatography A., 1229:148-55.

[15] Hallenbeck P.C., Leite G.B., Abdelaziz A.E.M., 2014. Exploring the diversity of microalgal physiology for applications in wastewater treatment and biofuel production. Algal Research, 6, Part A(0):111-8.

[16] Ji M.K., Abou-Shanab RAI., Kim S.H., Salama E.S., Lee S.H., Kabra A.N., Ji M.K. Abou-Shanab R.A.I., Kim S.H., Salama B.S., Lee S.H., Kabra A.N., Jeon B.H., 2013 Cultivation of microalgae species in tertiary municipal wastewater supplemented with $\mathrm{CO}_{2}$ for nutrient removal and biomass production. Ecological Engineering, 58(0):142-8

[17] Kassim M.A., Meng T.K., 2017. Carbon dioxide (CO2) biofixation by microalgae and its potential for biorefinery and biofuel production. Science of The Total Environment. Volumes 584-585, 15, Pages 1121-1129

[18] Largeau C., Casadevall E., Berkaloff C., Dhamelincourt P., 1980. Sites of accumulation and composition of hydrocarbons in Botryococcus-braunii. Phytochemistry, 19(6):1043-51.

[19] Leitão, R.C. , van Haandel, A.C., Zeeman,G., Lettinga G., 2006. The effects of operational and environmental variations on anaerobic wastewater treatmen systems: A review. Bioresource Technology, 97: 1105-1118.

[20] Lupi F.M., Fernandes H.M.L., Tome M.M., Sacorreia I., Novais J.M., 1994. Influence of nitrogen-source and photoperiod on exopolysaccharide synthesis by the microalga Botryococcus-braunii-UC-58. Enzyme and Microbial Technology, 16(7):546-50.

[21] Metzger P., Casadevall E., Coute A., 1988. Botryococcene distribution in strains of the green-alga Botryococcus-braunii. Phytochemistry, 27(5):1383-8.

[22] Metzger P., Largeau C.,2005. Botryococcus braunii: a rich source for hydrocarbons and related ether lipids. Applied Microbiology and Biotechnology.USA .66(5).

[23] Osundeko O., Davies H., Pittman J.K., 2013. Oxidative stress-tolerant microalgae strains are highly efficient for biofuel feedstock production on wastewater. Biomass and Bioenergy, 56(0):284-94.

[24] Pereira, C.M.P., Hobuss C.B., Maciel J.V., Ferreira L.R., Del Pino F.B., Mesko M.F., Jacob-Lopes E., Neto P.C., 2012. Biodiesel renovável derivado de microalgas: avanços e perspectivas tecnológicas. Química Nova, 35:2013-8.

[25] Ramaraj R., Tsai D.D-W, Chen P.H., 2014. Freshwater microalgae niche of air carbon dioxide mitigation. Ecological Engineering, 68(0):47-52.

[26] Razeghifard R., 2013. Algal biofuels, Photosynthesis Research, 117(1-3):207-19.

[27] Sydney E.B., da Silva T.E., Tokarski A., Novak A.C., de Carvalho J.C., Woiciecohwski A.L., Larroche C., Soccol C.R., 2011. Screening of microalgae with potential for biodiesel production and nutrient removal from treated domestic sewage. Applied Energy, 88(10):3291-4.

[28] Tran H-L., Kwon J-S., Kim Z.H, Oh Y, Lee C-G, 201 0. Statistical Optimization of Culture Media for Growth and Lipid Production of Botryococcus braunii LB572. Biotechnology and Bioprocess Engineering, 15(2):277-84.

[29] Unnithan V.V., Unc A., Smith G.B., 2014. Mini-review: A priori considerations for bacteria-algae interactions in algal biofuel systems receiving municipal wastewaters. Algal Research, 4(0):35-40.

[30] Wu Y-H., Yang J., Hu H-Y., Yu Y., 2013. Lipid-rich microalgal biomass production and nutrient removal by Haematococcus pluvialis in domestic secondary effluent. Ecological Engineering, 60(0):155-9. 